\title{
Virulence of entomopathogenic fungus, metarhizium anisopliae to sweetpotato whitefly, bemisia tabaci (hemiptera: aleyrodidae) under osmotic stress
}

\begin{abstract}
The aim of the present study was to investigate the virulence of the entomopathogenic fungus Metarhizium anisopliae (isolates PR1 and GT3) under osmotic stress condition. The virulence study of the fungus was conducted by three ways - growth (germination, vegetative growth and sporulation); enzymatic activities (chitinase, protease and lipase) of M. anisopliae and percentage mortality of Bemisia tabaci to M. anisopliae. Conidia of M. anisopliae were produced under different osmotic stress conditions as SDA medium as control, SDA medium with $0.5 \mathrm{M} \mathrm{NaCl}$, SDA medium with $0.5 \mathrm{M} \mathrm{KCl}$, SDA medium with $1 \mathrm{M} \mathrm{NaCl}$ and SDA medium with $1 \mathrm{M} \mathrm{KCl}$. The germination percentage, vegetative growth, sporulation, chitinase and protease activities were highest for control of PR1 isolate, reaching up to $97 \%, 4.1 \mathrm{~cm}$ and $6.6 \times 106$ conidia $/ \mathrm{ml}, 2.6 \mathrm{mU} / \mathrm{ml}$ and $1.7 \mu \mathrm{g} / \mathrm{ml} / \mathrm{min}$, respectively. These values decreased up to $86.7 \%, 3.6 \mathrm{~cm}$ and $4.1 \times 106$ conidia $/ \mathrm{ml}, 1.6 \mathrm{mU} / \mathrm{ml}$ and $1.0 \mu \mathrm{g} / \mathrm{ml} / \mathrm{min}$, respectively under osmotic stress. The lipase activity was highest for $0.5 \mathrm{M} \mathrm{NaCl}$ of PR1 isolate, reaching up to $18.2 \mu \mathrm{mol} / \mathrm{ml} / \mathrm{min}$. The mortality percentage of B. tabaci was highest for control of PR1 and GT3 isolates, reaching up to 83.9 and $83.8 \%$, respectively. These values decreased up to 77.4 and $77.5 \%$, respectively under osmotic stress. This paper concludes that both the isolate PR1 and GT3 are virulent to B. tabaci under osmotic stress condition.
\end{abstract}

Keyword: Plant protection; Biocontrol; Germination; Radial growth; Conidiogenesis;

Enzymatic activity; Mortality 